\title{
A Brief History of RCR Education
}

\section{Michael Kalichman}

\section{Abstract}

Responsible conduct of research (RCR) education is now common throughout the United States, primarily in response to federal requirements beginning with the National Institutes of Health in 1989. Despite this long history, RCR education programs remain highly disparate, often with illdefined content, format, and goals, and minimal evidence for effectiveness. However because it is widely believed that such programs can have value, it is hoped that a review of what is available, and how that came to pass, will highlight what has been done well and where gaps still remain.

\section{INTRODUCTION}

Over the past 25 years, programs for education in responsible conduct of research (RCR) have become increasingly common. Hundreds of RCR courses are taught each year in the U.S., and presumably far more seminars and workshops. With so much experience, it is reasonable to assume that the nature of such education is now well-defined. Surprisingly and unfortunately, those RCR education programs are characterized by highly disparate, and often ill-defined, content, format, and goals. Attempts to establish effectiveness have been only minimally successful. In this context, many RCR educators are concerned that rather than improving and supporting RCR programs, there are increasing calls to deregulate, to minimize expectations for mentoring about RCR, and to further lower nominal expectations for formal education. On the assumption that RCR programs do have --or at least can have-value, it is perhaps reasonable now to look back at how we got to this point.

Key questions to be answered are:

- $\quad$ What is RCR education?
- $\quad$ What was the nature of RCR education before federal requirements?
- $\quad$ How have federal requirements for RCR education evolved?
-
-

Corresponding Author: Michael Kalichman, Ph.D., Research Ethics Program, 0612, University of California, San Diego, La Jolla, California 92093-0612, 858-822-2027, Fax: 858-822-5765, kalichman@ucsd.edu. 


\section{WHAT IS RCR EDUCATION?}

The phrase "Responsible Conduct of Research" was probably used earlier, but it only entered wide usage after the National Institutes of Health (NIH) established a requirement for training in RCR in the late 1980s (NIH, 1989). Although the outlines of what we mean by RCR education may be referenced in these requirements, the specifics are not. Which of the vast number of potential ethical challenges faced by scientists should be addressed and how are not made clear by the general injunction to teach RCR. We have some guidance for what should be included based on NIH requirements for RCR education, but as noted below this guidance still falls far short of clear expectations for RCR education.

However, even without referencing the NIH requirement, these words (RCR) embody a goal that seems obvious. For research to be both valid and efficient, it is important that researchers adhere to good (responsible) practices. Presumably researchers will have learned the basics of responsibility (e.g., not to lie, cheat, or steal) before beginning their research career. It is also reasonable to assume that most researchers do not have serious character flaws that would keep them from exercising good judgment. Instead, the plausible domain of RCR education is those things that are not necessarily learned as part of a primary and secondary education (K-12). In other words, the focus of RCR education should be the specialized practices that constitute the responsible planning, conduct, and reporting of research. In short, the focus is on specifics of research that are handled in ways that are not self-evident.

Seen in this way, "responsible conduct of research" is more reminiscent of teaching good practice in science rather than teaching someone to not commit research misconduct. For example, in other settings we might talk about teaching students to be good citizens. We do not first think of inoculating them against committing crimes. Instead, the focus is something much more aspirational: to increase student awareness of the challenges they will face, to equip them to meet those challenges, and to persuade them that surmounting those challenges is worth the trouble. With this framing of the meaning of RCR, it is important to note that for the purposes of this discussion, the words "responsible conduct of research,

" "research ethics, " and "scientific integrity" can effectively be considered synonymous.

\section{WHAT WAS THE NATURE OF RCR EDUCATION BEFORE FEDERAL REQUIREMENTS?}

The concept that new researchers should be taught about responsible conduct of their research does not seem particularly radical, and it is fair to ask if they wouldn't just learn that conduct in the practice of learning how to do science. In fact, there is good reason to believe this is precisely what occurred historically. To a large extent, science for the past several hundred years has been defined by the next generation of scientists learning from mentors in the previous generation. Not unlike the apprentice model for teaching other trades, new scientists learned from established scientists how to conduct their science and how to do so responsibly. This concept of scientists teaching scientists is well illustrated by thoughtful biographies and manuals written by many well-respected scientists (e.g., Ramon y Cajal, 1916; Beveridge, 1950; Selye, 1964; Medawar, 1979; Kennedy, 1997). 
In theory, the apprentice model for RCR education should be enough, but beginning in the 1980s that no longer seemed to be the case. Several institutions established courses in research ethics and scientific integrity precisely because students appeared to have not learned fundamental issues important to the conduct of science. Two of the earliest examples were the University of Texas Health Science Center at Houston in 1984 (Bulger and Reiser, 1993) and Virginia Commonwealth University in 1986 (Macrina and Munro, 1993). In both cases, the premise was that mentoring was not sufficient and that it was necessary to supplement with formal courses. That premise was subsequently supported by data showing that mentors typically spent little or no time discussing or teaching their trainees the responsible conduct of research (Swazey and Anderson, 1998; Brown and Kalichman, 1998).

The observation that mentors were not in fact serving as mentors about RCR raises several questions. First, was this a result of a change from the way science was done in earlier years? Data to support this contention are not readily available, but it is fair to note that the landscape of science has changed. For example, the science and engineering workforce in the U.S. has more than doubled in size just since 1983, and increased by nearly 30 -fold from 182,000 in 1950 to 5.4 million in 2009 (NSF, 2012). By comparison, during the same period of time (1950-2009), total federal R\&D expenditures, in constant 2008 dollars, increased from $\$ 7.86$ billion to $\$ 137.17$ billion, an increase of just over 17-fold (AAAS, 2008). Therefore, roughly speaking, competition for resources doubled during this period of time.

Second, whether or not they did so in the past, why do so many mentors now apparently fail to teach RCR? One likely reason is that direct mentoring of trainees is hampered by demands on the typical faculty member, whose increased responsibility includes, but is not limited to: maintaining research funding, attending frequent meetings both national and international, and institutional administrative responsibilities. Anecdotally, these responsibilities are far greater now than 30 years ago. In this context, it is even more disturbing that many research supervisors may simply not recognize an academic duty to serve as mentors, such as described by Donald Kennedy (1997, pp. 97-116).

Third, even if many or most mentors do teach RCR, where does that leave those trainees with mentors who do not? This is largely a rhetorical question. Even if some trainees are learning what they need to know, there is good reason to believe that too many are not.

Finally, is it necessarily the case that we can rely on the quality of RCR mentoring? This question is one that was not likely to be asked before the advent of RCR education requirements. However now with two decades of teaching, experience, and research, it has become clear that the practice of science is replete with challenging questions about responsible conduct, many of which are evolving as science evolves. It is similarly clear that while the typical scientist may give substantial thought to such questions, few will have a comprehensive overview of the issues. And some cases of academic misconduct suggest that there are "mentors" who have given little thought to any of the issues. This and the above arguments are important factors favoring the creation of those initial RCR courses in the absence of federal requirements. 


\section{WHY WERE FEDERAL RCR EDUCATION REQUIREMENTS ESTABLISHED?}

Although RCR education is clearly the named purpose of federal requirements, it is difficult to avoid the impression that preventing research misconduct was the goal. Leading up to the first requirements, there were multiple cases of research misconduct during the late 1970s and the 1980s. Many of these were remarkable in their scope and severity. Notable examples include John Darsee who published 17 papers and over 50 abstracts based on fabrications and falsifications (Relman, 1983), Elias Alsabti who published as many as 60 plagiarized papers (Broad, 1980), and Robert Slutsky who published at least 12 fraudulent manuscripts (Engler et al., 1987).

At least as important as these cases of clear research misconduct were two other cases of alleged misconduct involving Thereza Imanishi-Kari and Robert Gallo. Both were particularly in the public eye, with testimony before Congress and the publication of books about each (e.g., Kevles, 1998; Crewdson, 2002). The high profile of these cases almost certainly galvanized recognition in the scientific community that not only the integrity of science, but also public support for science, was at risk. As noted by Steneck and Bulger (2007): "...biomedical scientists... under ...public scrutiny as a consequence of a decade of reports about misconduct in research, turned to formal education. "The result was a number of thoughtful reports, concluding, for example:

"Universities should provide formal instruction in good research practices. ... incorporated into various places in undergraduate and graduate curricula for all science students. "(Committee on the Responsible Conduct of Research, 1989, p. 30)

"...this required educational activity is essential ...to ensure that ... all individuals [including senior researchers and technicians] who perform research in institutional settings are sensitized to the ethical issues inherent in research. "(Commission on Research Integrity, 1995, p. 21)

Based on discussions with a variety of individuals at NIH and National Science Foundation (NSF) (personal communications, 1996-2012), opinions differ on whether the respective requirements (NIH, 1989; NIH, 1992; NSF, 2009) were motivated by research misconduct cases. On the one hand, it seems clear that research misconduct was prominently in the minds of scientists, regulators, and the public in the late 1980s (e.g., Committee on the Responsible Conduct of Research, 1989), and for the NSF in 2007. That almost certainly would have been a factor in arguing for RCR education requirements. And perhaps it was a necessary condition for proposed requirements to be sustained in the face of an academic community that would likely protest further government regulation. On the other hand, both agencies were and are keenly aware of the need to train and socialize the next generation of scientists - not just to avoid bad behavior, but to conduct science in a responsible fashion. This would mean, for example, the importance of keeping good research records. This raises a noteworthy irony. The two highest profile cases of alleged research misconduct in the 1980s were those of Imanishi-Kari and Gallo, both of whom were ultimately found not guilty of research misconduct, but clearly guilty of severely inadequate recordkeeping. While requirements for RCR education may have been reactions in part to research 
misconduct cases, the goal of such education is arguably first to promote responsible conduct and, at most secondarily, to decrease research misconduct.

One other impetus for RCR education deserves comment. In 1999, Jesse Gelsinger died while participating in a clinical trial designed to assess safety of gene transfer to correct a congenital deficit in ornithine transcarbamylase (Stolberg, 1999). This incident raised many questions about conflicts of interest, study design, and institutional and federal oversight (Steinbrook, 2008). However one noteworthy regulatory response was a new requirement that key personnel in NIH-funded human subjects research should be trained in the responsible conduct of research (NIH, 2000). Although sometimes viewed as an RCR requirement, it appears to typically be implemented with a narrower focus on human subjects research, consistent with the text of the requirement: "...education on the protection of human research participants" (NIH, 2000).

\section{HOW HAVE FEDERAL REQUIREMENTS FOR RCR EDUCATION EVOLVED?}

The past two decades have resulted in four different versions of topics to be covered under NIH or Public Health Service (PHS) requirements for RCR education. These topics are summarized in Table 1 of Kalichman (2013). While the wording has varied slightly, 5 topics (conflict of interest, data management, authorship and publication, research misconduct, and human and animal subjects) have been retained in all 4 versions of these requirements. Mentoring, collaboration, and peer review are three newer elements first introduced with the PHS (2000) requirement, which was later suspended (NIH, 2001), but all of which were retained in the $2009 \mathrm{NIH}$ guidelines (NIH, 2009). It is interesting to note that more aspirational goals of looking at "professional standards and codes of conduct,... bioethics, research conduct, ideals of science, etc." (NIH, 1989) seems to have been lost after 1989 (NIH, 1992; PHS, 2000), but arguably returned with the NIH update in 2009 (NIH, 2009): "scientist as a responsible member of society, contemporary ethical issues in biomedical research, and the environmental and societal impacts of scientific research."

Despite the apparent specificity about what should be covered, guidance is in fact minimal. It would not be terribly different if someone were instructed simply to teach mathematics, or biology, or linguistics. The question unanswered is what about the listed topics should be taught. Using "conflicts of interest" as an example, the range of content that might be covered is wide-ranging (Table 1). The list is long. It is unrealistic to expect that all should be or is covered. Whether there are some elements that should always be covered, or if it doesn't matter which elements are covered as long as some are included, is a question not addressed by the requirements.

In terms of formats for training, the most recent of the four NIH requirements (NIH, 2009) has been the most clear. Key elements include in-person programs (i.e., not solely online training), face-to-face discussion, with faculty involvement, at least 8 hours in duration, and no less frequently than once every four years and at each career stage. The duration requirement is noteworthy. With 9 topic areas to be covered, that's less than an hour per topic. Even if a course were extended to 15 or 20 hours, instructors have many choices to 
make about which of many possible goals will be met within the short time available for each topic.

\section{WHAT RESOURCES WERE DEVELOPED TO MEET THOSE REQUIREMENTS?}

Prior to the announcement of the NIH RCR requirement in 1989, there were virtually no formal resources available for prospective teachers of research ethics. In that same year, the first edition of On Being a Scientist was published by the National Academy of Sciences (NAS) (NAS Committee on the Conduct of Sciences, 1989). Subsequently, the quantity and variety of resources for teaching RCR proliferated at a remarkable rate. There is no lack of materials or curricula as demonstrated by the following selected sampling of the many resources now available. Within a few years after the NAS publication, several noteworthy contributions included texts from Bulger et al. (1993), Korenman and Shipp (1994), Bebeau et al. (1995), Macrina (1995), Penslar (1995), Elliott and Stern (1997) and Stern and Elliott (1997). Much of this material was based on courses and teaching that pre-dated the NIH requirement. Nearly all of it emphasized the importance of cases, discussion, and student engagement as the best means to teach RCR.

In addition to a growing number of written cases, both real and contrived, the American Association for the Advancement of Science (AAAS) produced 5 multi-layered video cases (AAAS, 1996). Video enactments of researchers interacting add a valuable element of realism, and a reminder of the roles of human relationships in defining ethical challenges. These AAAS videos continue to be available, and have been complemented now by numerous video projects. Prominent examples include: University of Alabama Birmingham (Vollmer, 2003), Syracuse University Graduate School (2004), Laboratory Management Institute of UC Davis (2010), University of Nebraska Lincoln and West Virginia University (Vasgird et al., 2011), and Office of Research Integrity (ORI, 2011).

To address the increase in resources in the 1990s, ORI provided startup support in 1999 for an online project to serve as a portal for prospective RCR teachers. This project, developed at UC San Diego, was initially hosted at the domain name rcr.ucsd.edu, but has since evolved based on various sources of funding to become "Resources for Research Ethics Education" (http://research-ethics.net). Initially, it was feasible for a single site to largely cover all available resources. However as the number and kind of resources evolved, it became clear that one site was insufficient. During the following decade, the number of online resources increased dramatically both for individual programs, and for national resources. In addition to the ORI (http://ori.hhs.gov), several noteworthy examples still active include:

- $\quad$ Ethics CORE (Collaborative Online Resource Environment), University of Illinois Urbana-Champaign http://nationalethicscenter.org

- Ethics Education Library, Illinois Institute of Technology http:// ethics.iit.edu/eelibrary 
$\bullet$

-

Fostering Integrity in Research, Scholarship and Teaching (FIRST), Univ of Minnesota http://www.research.umn.edu/ethics

Online Ethics Center for Engineering and Research, National Academy of Engineering http://www.onlineethics.org

Project for Scholarly Integrity, Council of Graduate Schools http:// www.scholarlyintegrity.org

Responsible Conduct of Research for Postdocs, National Postdoctoral Association http://www.nationalpostdoc.org/publications/rcr

As more and more material became accessible on the Internet, interest in Internet-based research ethics education also increased. Internet-based courses took a variety of forms as summarized in Table 2. An entire issue of the journal Science and Engineering Ethics was dedicated to commentaries and original articles on Internet education in ethics (Sieber and Bird, 2005). While considerable potential was seen in the medium, the authors made clear that such programs are not panaceas, nor are they cheap or easy to create.

With increased expectations for teaching of RCR, and the accumulated experience in some centers, several train-the-trainer programs were developed beginning with Ken Pimple's Teaching Research Ethics at Indiana University in 1993 (Taubes, 1995a) and Michael Zigmond and Beth Fischer's Survival Skills and Ethics at the University of Pittsburgh in 1995 (Taubes, 1995b). In 2000, Francis Macrina of Virginia Commonwealth University and the author (MK) taught the first of many RCR101 train-the-trainer research ethics workshops under the auspices of PRIM\&R (Public Responsibility in Medicine \& Research), and subsequently have continued teaching workshops nationally and internationally (http:// research-ethics.net/educational-settings/train-the-trainer/\#resources).

As the number of people working in RCR education increased, various meetings and organizations were convened to share experience, resources, and perspectives. Beginning as early as 1990, the ORI played a primary role in bringing leaders in the RCR field together. For a decade, these conferences were typically collaborations with scientific societies (e.g., AAAS, CGS, NCURA) and universities (e.g., University of Arizona, University of Michigan). In 2000, the ORI sponsored the first Research on Research Integrity conference with over 40 presentations on various aspects of research standards, teaching research integrity, and current research on research integrity. The Research on Research Integrity conference was repeated periodically with meetings in 2002, 2004, 2006, and 2009. It has been largely replaced by what is now known as the World Conference on Research Integrity, which met in Lisbon in 2007, Singapore in 2010, and Montreal in 2013. A more focused RCR Summit was convened in 2001 in Bethesda with $~ 40$ national leaders in RCR education. The purpose of the meeting was to identify next steps for the field in light of increasing requirements from the PHS and NIH for RCR training. A second RCR summit, open to the RCR community ("A National Dialogue on Future Directions of RCR") was cosponsored by the ORI and Michigan State University in 2004.

While a number of organizations, such as PRIM\&R, CGS, and others, periodically hosted programs on RCR, it was apparent in the 2001 RCR Summit in Bethesda that there was no 
national, non-governmental organization to specifically serve the RCR community. With pressures to increase RCR education, participants in that meeting urged the creation of such an organization. The result was the founding of the Responsible Conduct of Research Education Consortium (RCREC) at UC San Diego in 2004, which evolved to become the Responsible Conduct of Research Education Committee (RCREC) hosted by the Association for Practical and Professional Ethics in 2006 (Kalichman, 2007). This organization was designed to be a partnership of research institutions nationally and at one point had over 90 members. While the RCREC was positioned to fill an important need, institutional memberships waned in favor of working individually rather than remaining part of a collective effort. Given that those institutions might still benefit from, or prefer to take advantage of, the many different existing national and international projects in support of RCR education, Philip Langlais of Old Dominion University and the author (MK) collaborated with the Council of Graduate Schools to host a meeting of national leaders in April of 2009. The purpose of this group, later named the National Advisory Panel on Research Integrity (NAPRI), was to promote mutual awareness and collaboration among the many efforts that often pursued overlapping and competing goals (Langlais and Kalichman, 2009, http://research-ethics. net/introduction/NAPRI). While increased awareness was almost certainly achieved initially, NAPRI is not currently active.

\section{HOW IS IT WORKING?}

It should be clear that the curricula and resources for RCR education are extensive. With so many tools at our fingertips, it is fair to ask are they sufficient? Is RCR education working? The answer is an unequivocal "We don't know." There are many reasons why we don't know. Because those reasons are part of the current RCR education landscape it is worth noting them here:

1. Reported goals are diverse: In an attempt to identify common, clear goals for RCR education, Kalichman and Plemmons (2007) interviewed 50 RCR instructors. Goals were found to be highly diverse and not always well thought out as pedagogical aims. Without consensus about the purpose of RCR education, it is not possible to assess success in meeting a purpose.

2. Requirement not taken seriously: A secondary finding of the goals study (Kalichman and Plemmons, 2007) was that "despite having been identified by $[\mathrm{NIH}]$ training grant directors as teachers of required RCR courses, nearly $25 \%$...reported that they were not actually RCR instructors, and $22 \%$ of those interviewed were not aware that NIH trainees were required to take their courses." The failure of training grant directors to know who is teaching their required RCR courses is not consistent with the hypothesis that those directors consider RCR training a high priority.

3. Reported content and approaches are diverse: The one systematic national attempt to assess contents and approaches in existing RCR education courses (Mastroianni and Kahn, 1999) found considerable diversity in content (e.g., nearly "1/3 of the T32 programs covered three or fewer of the [five NIH recommended] categories"). And the approaches used were 
similarly diverse, including various combinations of lecture, seminar, brown bag, small group discussion, and use of case studies. A more recent study with a focus on training in Clinical and Translational Science Awards similarly found "significant variation in scope, content, and approaches to RCR instruction" (DuBois et al., 2010).

4.

Requirements unclear: As noted above, even if a particular topic (e.g., conflict of interest) is commonly taught at two or more institutions, there is no reason in the absence of guidance or guidelines to believe that what is covered will be or should be the same.

5.

Nominal evidence of effectiveness: Based on a meta-analysis of published studies, the effect of RCR education on ethical decision making is modest at best (Antes et al., 2010); various studies have found no changes in various other outcome measures (e.g., Drake et al., 2005; Kalichman and Friedman, 1991; Schmaling and Blume, 2009); and unfortunately some studies have suggested negative impacts of RCR teaching (Eastwood et al., 1996; Anderson et al., 2007; Heitman et al., 2001). These results are to be expected given the items noted above.

Taken together, it is hard to imagine an outcome measure nationally that should have improved as a result of the RCR education enterprise as it's now constituted. However that's not an indictment of the curricula and resources we have for RCR education. We already have more than enough curricular resources; we now need to figure out what to do with them. The question still unanswered is what goals we should set for ourselves and what we can do to promote the quality of teaching. Before the value of RCR education might be assessed for an individual course or program, it is important to be clear about what meaningful and realistic goals we wish to accomplish. Before the value of RCR education might be assessed nationally, we must first identify common goals as well as ensure that the RCR instructors are adequately motivated and prepared to take the lead.

\section{Acknowledgments}

This manuscript is based on a talk prepared by the author for presentation at the "ORI at 20: Reassessing Research Integrity" Leadership Conference sponsored by the Office of Research Integrity (ORI) and Johns Hopkins University in Baltimore, Maryland on April 4, 2013. Because of illness, the author was unable to attend, and thanks Ken Pimple of Indiana University for presenting in his place. In addition, Philip Langlais (Old Dominion University) and Daniel Vasgird (West Virginia University) are thanked for their thoughtful review of this manuscript and many helpful suggestions, and Ken Pimple and Nicholas Steneck (University of Michigan) are thanked for helpful conversations before and after the meeting. This work was partially supported by the National Science Foundation (NSF), Grant 1135358, and the National Institutes of Health (NIH), Grant UL1TR000100. The content and opinions are solely the responsibility of the author and do not necessarily represent the official views of the NSF or NIH.

\section{REFERENCES}

AAAS. Produced by Amram Nowak Associates, Inc., with assistance from the Medical College of Georgia, for the American Association for the Advancement of Science, Directorate for Science and Policy Programs. Washington, DC: 1996. Integrity in Scientific Research: Five Video Vignettes. http://www.aaas.org/spp/video

AAAS. Trends in Federal R\&D by Function, FY 1949-2009. Based on OMB Historical Tables in Budget of the United States Government FY 2009. 2008 http://www.aaas.org/spp/rd/histda09tb.pdf. 
Anderson MS, Horn AS, Risbey KR, Ronning EA, DeVries R, Martinson BC. What Do Mentoring and Training in the Responsible Conduct of Research Have To Do with Scientists' Misbehavior? Findings from a National Survey of NIH-Funded Scientists. Academic Medicine. 2007; 82(9):853860. [PubMed: 17726390]

Antes AL, Wang X, Mumford MD, Brown RP, Connelly S, Devenport LD. Evaluating the effects that existing instruction on responsible conduct of research has on ethical decision making. Academic Medicine. 2010; 85(3):519-526. [PubMed: 20182131]

Bebeau, MJ.; Pimple, KD.; Muskavitch, KMT.; Borden, SL.; Smith, DH. Moral Reasoning in Scientific Research: Cases for Teaching and Assessment. Bloomington, IN: Poynter Center for the Study of Ethics and American Institutions, Indiana University; 1995.

Beveridge, WIB. The Art of Scientific Investigation. New York: Vintage Books; 1950.

Broad WJ. Would-Be Academician Pirates Papers. Science. 1980; 208:1438-1440. [PubMed: 17796686]

Brown S, Kalichman MW. Effects of training in the responsible conduct of research: A survey of graduate students in experimental sciences. Science and Engineering Ethics. 1998; 4(4):487-498. [PubMed: 11658057]

Bulger, RE.; Heitman, E.; Reiser, SJ., editors. The Ethical Dimensions of the Biological Sciences. New York: Cambridge University Press; 1993.

Bulger RE, Reiser SJ. Studying science in the context of ethics. Academic Medicine. 1993; 68(9 suppl):S5-S9. [PubMed: 8373491]

Commission on Research Integrity. Report to the Secretary of Health and Human Services, the House Committee on Commerce, and the Senate Committee on Labor and Human Resources. Integrity and misconduct in research. 1995

Institute of Medicine. , editor. Committee on the Responsible Conduct of Research. The Responsible Conduct of Research in the Health Sciences. Washington, DC: National Academies Press; 1989.

Crewdson, J. Science Fictions: A Scientific Mystery, a Massive Cover-Up, and the Dark Legacy of Robert Gallo. New York: Little Brown \& Co; 2002.

Drake M, Griffin P, Kirkman R, Swann J. Engineering Ethical Curricula: Assessment and Comparison of Two Approaches. Journal of Engineering Education. 2005; 94:223-231.

DuBois JM, Schilling DA, Heitman E, Steneck NH, Kon AA. Instruction in the Responsible Conduct of Research: An Inventory of Programs and Materials within CTSAs. Clinical and Translational Science. 2010; 3(3):109-111. [PubMed: 20590680]

Eastwood S, Derish P, Leash E, Ordway S. Ethical issues in biomedical research: Perceptions and practices of postdoctoral research fellows responding to a survey. Science and Engineering Ethics. 1996; 2:89-114. [PubMed: 11657788]

Elliott, D.; Stern, JE. Research Ethics: A Reader. Hanover, NH: University Press of New England; 1997.

Engler RL, Covell JW, Friedman PJ, Kitcher PS, Peters RM. Misrepresentation and responsibility in medical research. New England Journal of Medicine. 1987; 317(22):1383-1389. [PubMed: 3317039]

Heitman E, Salis PJ, Bulger RE. Teaching Ethics in Biomedical Science: Effects on Moral Reasoning Skills. Proceedings of the First ORI Research Conference on Research Integrity. 2001:195-202.

Kalichman M. Why do we teach research ethics? Proceedings from National Academy of Engineering Workshop on Practical Guidance on Science and Engineering Ethics Education. 2013 (forthcoming).

Kalichman MW. Responding to challenges in educating for the responsible conduct of research. Academic Medicine. 2007; 82(9):870-875. [PubMed: 17726394]

Kalichman MW, Friedman PJ. A pilot study of biomedical trainees' perceptions concerning research ethics. Academic Medicine. 1992; 67:769-775. [PubMed: 1418260]

Kalichman MW, Plemmons D. Reported Goals for Responsible Conduct of Research Courses. Academic Medicine. 2007; 82(9):846-851. [PubMed: 17726389]

Kennedy, D. Academic Duty. Cambridge, MA: Harvard University Press; 1997. 
Kevles, DJ. The Baltimore Case: A Trial of Politics, Science, and Character. New York: W.W. Norton \& Co.; 1998.

Korenman, SG.; Shipp, AC. Teaching the responsible conduct of research through a case study approach: a handbook for instructors. Washington, DC: Association of American Medical Colleges; 1994.

Laboratory Management Institute. Lab Management Video Vignettes. UC Davis; 2010. http:// learning.ucdavis.edu/LabAct

Langlais P, Kalichman M. National panel recommends new direction in research ethics \& integrity education. Office of Research Integrity Newsletter. 2009; 17(3):6.

Macrina, FL. Scientific Integrity: An Introductory Text with Cases. Washington, DC: American Society for Microbiology Press; 1995.

Macrina FL, Munro CL. Graduate teaching in principles of scientific integrity. Academic Medicine. 1993; 68(12):879-886. [PubMed: 8259956]

Mann MD. A web-based course in research ethics. Society for Neuroscience Abstracts. 1999; 25:262.

Mastroianni AC, Kahn JP. Encouraging accountability in research: a pilot assessment of training efforts. Accountability in Research. 1999; 7(1):85-100. [PubMed: 11657564]

Medawar, PB. Advice to a Young Scientist. Philadelphia: Harper \& Row; 1979.

NAS Committee on the Conduct of Sciences. On Being a Scientist. Proceedings of the National Academy of Sciences USA. 1989; 86:9053-9074. http://www.pnas.org/content/ 86/23/9053.full.pdf.

NIH. Requirement for programs on the responsible conduct of research in national research service award institutional training programs. NIH Guide for Grants and Contracts. 1989; 18(45):1. http:// grants.nih.gov/grants/guide/historical/1989_12_22_Vol_18_No_45.pdf.

NIH. Reminder and Update: Requirement for Instruction in the Responsible Conduct of Research in National Research Service Award Institutional Training Grants. NIH Guide. 1992; 21(43) http:// grants.nih.gov/grants/guide/notice-files/not92-236.html.

NIH. Required education in the protection of human research participants. 2000 [June 5, 2000] NOTICE: OD-00-039. http://grants.nih.gov/grants/guide/notice-files/not-od-00-039.html.

NIH. Notice of suspension of "PHS Policy on Instruction in the Responsible Conduct of Research.". 2001 [February 22, 2001] NOTICE: OD-01-020. http:/grants.nih.gov/grants/guide/noticefiles/ NOT-OD-01-020.html.

NIH. Update on the Requirement for Instruction in the Responsible Conduct of Research. 2009 [Release Date: November 24, 2009] NOTICE: OD-10-019. http:/grants.nih.gov/grants/guide/ noticefiles/NOT-OD-10-019.html.

NSF. B. Responsible Conduct of Research. Proposal and Award Policies and Procedures Guide. Part II - Award and Administration Guidelines, p. IV-3. 2009 http://www.nsf.gov/pubs/policydocs/ pappguide/nsf10_1/nsf10_1.pdf.

NSF. Science and Engineering Indicators 2012. 2012 http://www.nsf.gov/statistics/seind12.

ORI. The Lab: Avoiding Research Misconduct. Released and Distributed by the Office of Research Integrity. 2011 http://ori.hhs.gov/thelab.

Penslar, RL., editor. Research Ethics: Cases \& Materials. Bloomington, IN: Indiana University Press; 1995.

PHS. PHS Policy on Instruction in the Responsible Conduct of Research (RCR). 2000 Announced: December 5, 2000. NOTICE: OD-01-007. http://grants.nih.gov/grants/guide/notice-files/NOTOD-01-007.html.

Pimple KD. Ethics at the Interface: A Successful Online Seminar - Commentary on 'Reflections on Teaching Health Care Ethics on the Web' (T. Schonfeld). Science and Engineering Ethics. 2005; 11(2):495-499. [PubMed: 16190290]

Ramon y Cajal, S. Translation: Advice for a Young Investigator. Cambridge, MA: MIT Press; 1916. Reglas y Consejos sobre Investigación Biológia. 1999

Relman AS. Lessons from the Darsee Affair. New England Journal of Medicine. 1983; 308:14151417. [PubMed: 6843634] 
Steinbrook, R. The Gelsinger Case. In: Emanuel, EJ.; Grady, CC.; Crouch, RA.; Reidar, KL.; Miller, FG.; Wendler, DD., editors. The Oxford Textbook of Clinical Research Ethics. New York, NY: Oxford University Press; 2008. p. 110-120.

Stolberg, SG. The biotech death of Jesse Gelsinger. New York Times; 1999. http://www.nytimes.com/ 1999/11/28/magazine/the-biotech-death-of-jesse-gelsinger.html

Schmaling KB, Blume AW. Ethics instruction increases graduate students' responsible conduct of research knowledge but not moral reasoning. Accountability in Research. 2009; 16(5):268-283. [PubMed: 19757232]

Selye, H. From Dream to Discovery: On Being a Scientist. New York: McGraw-Hill; 1964.

Sieber J, Bird SJ. Web-Based Ethics Education in Science and Engineering. Science and Engineering Ethics. 2005; 11(3):323-511.

Steneck NH, Bulger RE. The history, purpose, and future of instruction in the responsible conduct of research. Academic Medicine. 2007; 82(9):829-834. [PubMed: 17726385]

Stern, JE.; Elliott, D. The Ethics of Scientific Research: A Guidebook for Course Development. Hanover, NH: University Press of New England; 1997.

Swazey, JP.; Anderson, MS. Mentors, Advisors, and Role Models in Graduate and Professional Education. In: Rubin, ER., editor. Mission Management. Washington, DC: Association of Academic Health Centers; 1998.

Syracuse University Graduate School. Research Ethics Video Vignettes. 2004 http://www.syr.edu/ gradschool/gsprograms/resources/REandAIvideos.html.

Taubes G. Indiana: Wrong Answers — But No Right Ones. Science. 1995a; 268:1707. [PubMed: 7792590]

Taubes G. Pittsburgh: Interwoven With the Fabric of Learning. Science. 1995b; 268:1709. [PubMed: 7792591]

Vasgird D, Kincaid C, Smith V. Case Study Videos. Funded by National Science Foundation grant to Council of Graduate Schools and the Collaborative Institutional Training Initiative. 2011 http:// oric.research.wvu.edu/rcr_train/rcr-education-and-training\#videos.

Vollmer, S. University of Alabama Birmingham; 2003. In the Lab, Mentors and Students Behind the Scenes. http://media.iitonline.iit.edu/research/inthelab/part1; http://media.iitonline.iit.edu/research/ inthelab/part2; http://media.iitonline.iit.edu/research/inthelab/part3 


\section{Table 1}

Examples of the many issues that might be a focus for the topic of conflict of interest.

Financial conflicts of interest
Federal regulations governing such conflicts
State or institutional regulations
Other kinds of conflicting interests such as desire to publish or for advancement
Historical evidence of bias due to financial conflicts
Evidence of bias due to other kinds of conflicts
The need to avoid conflicts
The need to find ways to manage unavoidable conflicts
Methods for decreasing the risk of bias in the design of experiments
The importance of disclosure in publications
The insufficient value of disclosure as a tool to protect against bias


Table 2

Four categories of Internet-based education in research ethics.

\begin{tabular}{|c|c|c|}
\hline Type & $\begin{array}{l}\text { Student online } \\
\text { access to }\end{array}$ & Examples \\
\hline Resources & $\begin{array}{l}\text { Posting of information } \\
\text { about research ethics } \\
\text { without } \\
\text { documentation of } \\
\text { participation or } \\
\text { mastery }\end{array}$ & $\begin{array}{l}\text { See links at: } \\
\text { http://research-ethics.net/introduction/portal }\end{array}$ \\
\hline Supplementary & $\begin{array}{l}\text { Syllabus and other } \\
\text { resources to } \\
\text { supplement an in- } \\
\text { person course }\end{array}$ & $\begin{array}{l}\text { Scientific Ethics at UC San Diego: } \\
\text { http://ethics.ucsd.edu/courses/ethics }\end{array}$ \\
\hline Tutorial & $\begin{array}{l}\text { Materials coupled } \\
\text { with questions } \\
\text { (typically multiple } \\
\text { choice) to assess } \\
\text { completion and } \\
\text { understanding }\end{array}$ & $\begin{array}{l}\text { Course in the Responsible Conduct of Research, CITI } \\
\text { https://www.citiprogram.org/rcrpage.asp } \\
\text { Responsible Conduct of Research, CMDITR } \\
\text { http://nationalethicscenter.org/index.php?option=com_rcrtutorial } \\
\text { Responsible Conduct of Research, Columbia University } \\
\text { http://ccnmtl.columbia.edu/projects/rcr } \\
\text { Program for Education and Evaluation in Responsible Research and } \\
\text { Scholarship, University of Michigan } \\
\text { http://my.research.umich.edu/peerrs }\end{array}$ \\
\hline Course & $\begin{array}{l}\text { Syllabus and other } \\
\text { resources to } \\
\text { supplement an online } \\
\text { learning environment } \\
\text { to interact with other } \\
\text { students and/or the } \\
\text { instructor by } \\
\text { discussion boards, e- } \\
\text { mail conversations, } \\
\text { instant messaging, etc. }\end{array}$ & $\begin{array}{l}\text { Research Ethics, U Nebraska Medical Center (1999-2005) } \\
\text { (Mann, 1999) } \\
\text { Scientists and Subjects, Indiana University (1999-2006) (Pimple, 2005) } \\
\text { Scientific Integrity, UC San Diego (1999-present): } \\
\text { http://ethics.ucsd.edu/courses/integrity }\end{array}$ \\
\hline
\end{tabular}

